
\title{
Questions of direction
}

\section{Top-down versus bottom-up.}

\section{David Lindley}

A few years ago, I had a conversation with an editor about the possibility of writing a book on global warming and climate change. There had been a lot of stories in the newspapers about new measurements of global average temperature, the difficulty of establishing trends, the lack of a good understanding of climatic and atmospheric changes in the Earth's past, and so on. No one really knew what was going on and what the implications were. I could write a book laying out the scientific arguments with all their uncertainties and unknowns, and showing why this was such a confusing subject.

But confusion is not a big selling point. The editor wanted to know whether the planet was really getting warmer or not. Probably, I said, but it's not clear how quickly. This was not an attractive answer. I got the impression that this editor would be interested in a book that said either (a) global warming is a huge hoax, there's nothing to worry about, or else (b) New York City will be under a metre of water in 30 years' time. Conspiracies and disasters have market potential.

I never wrote the book. It probably would have been a little dry. Useful and illuminating, no doubt, but how many people really want to read a dispassionate and thorough account demonstrating that a complex issue is, in fact, truly complex? That's what university presses are for.

It's a trite complaint that journalists and science writers oversimplify, turning all shades of grey into black or white. It makes for a clearer message and (perhaps) it sells better. But scientists themselves are just as apt to promote seemingly simple answers to complicated questions, in the interests of getting their point of view across.

At the heart of Stephen Hawking's Brief History of Time, for example, is the idea that fundamental physical laws can determine the whole course of cosmic history, with the particular proposal that something called

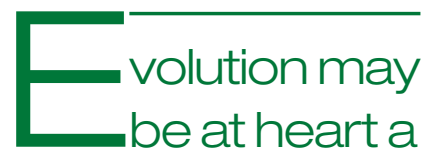

simple idea, but its ramifications are almost infinitely complex. the 'no boundary condition' can sweep a lot of uncertainties under the carpet. Richard Dawkins has pushed the idea of "selfish" genes, so that even apparently altruistic acts are to be explained as the result of one collection of genes improving its chances by assisting in the survival of other bodies carrying the same genes. I remember how appealingly powerful Dawkins made this idea sound, yet I couldn't help thinking that the wool was being pulled over my eyes. How, after all, does one hyena know that some other hyena is its second cousin, so it can calculate the degree of risk it's willing to take protecting the other animal?

Simple ideas with apparently far-reaching implications seem to hold out the hope of resolving difficult and murky questions. Why is the Universe the way it is? Why do animals do the things they do?

On the other hand, as Oscar Wilde warned, "the truth is rarely pure and never simple". Science may, on occasion (and perhaps in theoretical physics above all), generate simple, elegant explanations of vast power and reach. But this is not necessarily the rule, even in physics, nor a good model for science in general. Evolution, for instance, may be at heart a simple idea, but its ramifications are almost infinitely complex, and it certainly doesn't lead to simple predictions in the way that general relativity does.

Whether one prefers science to be simple or complicated may be essentially a matter of psychology. Edward O. Wilson, in his recent book Consilience: The Unity of Knowledge, argues that the disparate areas of science are fundamentally of a piece, and moreover that science can in principle offer rational accounts of all manner of seemingly unscientific things, extending even to artistic creativity. Wilson is eloquent and passionate as always, but the world he conjures, although compelling to many, seems dreary to me - the intellectual equivalent of the globalization of human culture.

There may be an unbridgeable divide between those who hanker after grand systems and those who revel in detail, complexity and even ambiguity. As a physicist turned writer, I seem to be moving from the first camp to the second. I don't think imposition of an arbitrary 'no boundary condition' can explain all that much about the Universe. I think there's more to life than the selfishness of genes. I don't think Wilson will ever be able to furnish a scientific explanation of why, the older I get, the more I like Haydn.

A recent trend in popular science publishing suits my changing philosophy.

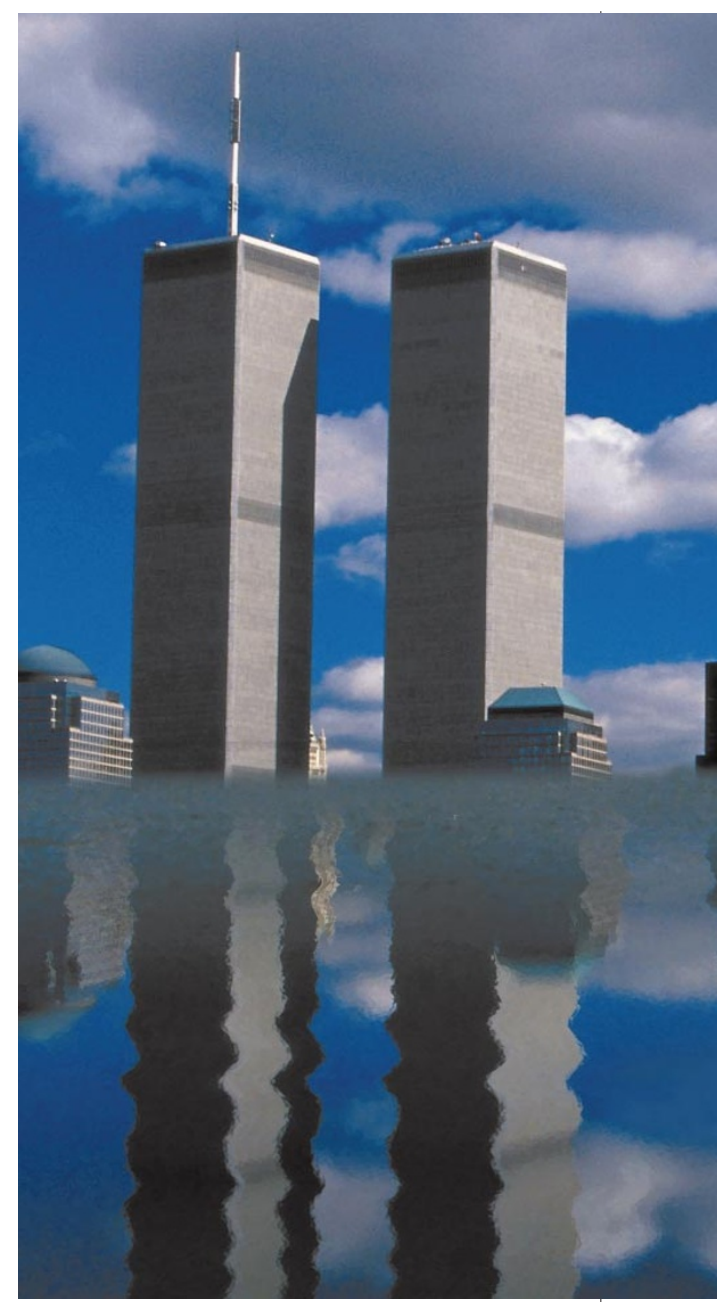

Dava Sobel's Longitude is the archetype. The ability to sail around the world without crashing into rocks is a big theme, of course, but the attractions of the book are in the story-telling and the accumulation of incident. A couple of recent books on the mathematical concept of 'zero' work in somewhat the same way, tackling a big subject by means of the sharp detail and the telling anecdote.

This, it seems to me, is not only a more interesting way of writing about science, but a more honest and effective one. Science grows in a piecemeal, haphazard fashion more often than it does by blinding flashes of insight, and writing that reflects the erratic and zigzag growth of scientific knowledge is ultimately more persuasive and enlightening.

So perhaps that book on global warming could be written after all. Delve into the history of weather records, from the obsessive diaries of eccentric country curates to today's world-spanning technology. Show, don't tell, how the big picture arises by the aggregation and resolution of often contradictory minutiae. Make plain, above all, why scientists can be both knowledgeable and uncertain.

David Lindley is a writer currently living in Arlington, Virginia, USA. 